\title{
The status of heavy metal levels in a Ramsar Site, Kuala Gula Bird Sanctuary: the impact of the anthropogenic inputs.
}

\begin{abstract}
Distributions of $\mathrm{Cd}, \mathrm{Cu}, \mathrm{Pb}$, and $\mathrm{Zn}$ in the surface sediments from two sites of the Kuala Gula Bird Sanctuary, Malaysia were monitored for a period of 6 months from October 2006 to March 2007. In December 2006, the concentration of $\mathrm{Zn}$ in one location was significantly ( p50.05) higher (3.91.3 mgkg1) than the other metals at both sites, but in the oxidizable organic fraction it was highest at both sites during October; with mean concentrations of $18 \mathrm{mg} \mathrm{kg} 1$ at both locations. In the acid-reducible fraction, high concentrations of $\mathrm{Pb}(2.3 \mathrm{mg}$ kg1) were detected at station 2 in February 2007, being highest among all four metals at both stations. The acid-reducible fraction found in $\mathrm{Pb}$ ranged from $0.10 \%$ to $3.1 \%$ in both stations. Percentages ranging from $51 \%$ to $96 \%$ were observed for all four metals in the resistant fraction throughout the sampling period. These results indicate low contributions from anthropogenic sources. The findings constitute a baseline data archive for future reference.
\end{abstract}

Keyword: Geochemical fractionionation; Metals; Intertidal mudflat; Sediments; Ramsar site, Kuala Gula. 